\title{
Study on the Optimization of the Soluble Dietary Fiber Content of Soybean Residue by Steam Explosion Pretreatment
}

\author{
TongSop $\mathrm{Ri}^{1}$, SongRok $\mathrm{Uh}^{2}$, ChonBong Song ${ }^{1}$, HyonDok Pak ${ }^{1}$, YongChol Ju${ }^{3}$, SongNam $\mathrm{Ri}^{1}$, OkJong Zhang ${ }^{1}$ \\ ${ }^{1}$ Pyongyang Han TokSu University of Light Industry, Pyongyang, Democratic People's Republic of Korea \\ 2Pyongyang Jang CholGu University of Commerce, Pyongyang, Democratic People's Republic of Korea \\ ${ }^{3}$ Wonsan University of Agriculture, Wonsan, Democratic People's Republic of Korea
}

\begin{abstract}
Article Info

Volume 8, Issue 3

Page Number: 36-39

Publication Issue :

May-June-2021

\section{Article History}

Accepted : 05 May 2021

Published: 12 May 2021

Because a large amount of soybean residue(SR) what is the byproduct of tofu and soymilk industries is produced annually in the world and is a byproduct with a rich nutritional profile, particularly in proteins, fibers, lipids, and bioactive components, a lot of researchers intensify the study on the SR and the processing and utilization of its have attracted more and more attention due to the increased consumption of SR in recent years. Especially the soluble fiber of SR lowers blood cholesterol and triglyceride levels by binding to cholesterol and helping to pass it out of the body, therefore, the composition proportion of soluble components in dietary fiber is an important factor affecting its physiological function. Steam explosion (SE) is a kind of physical method recently used in food pretreatment. In this study, the insoluble dietary fiber of SR converted to soluble dietary fiber by SE treatment and increased the content of soluble dietary fiber, and optimized the condition of SE treatment processing by response surface methodology (RSM). The results showed that the optimum conditions was: moisture content of $76.3 \%$, steam explosion time of $88 \mathrm{~S}$, steam explosion pressure of $1.7 \mathrm{MPa}$; on the conditions, the content of SDF was $36.5 \%$. Through the analysis on the physicochemical properties of SE treated SR in the optimum condition, determined that water solubility of SR increased significantly, while swelling capacity, oil and water holding capacities decreased after SE treatment.
\end{abstract}

Keywords : Soybean residue, Steam explosion, Soluble dietary fiber, response surface method

\section{INTRODUCTION}

Soybean residue(SR), also named Okara, is the by-pro duct of tofu and soymilk industries. A large amount of SR is produced annually in the world, but only a smal 1 amount is utilized with the increase of soybean cons umption [1]. However, the utilization of SR is very lo $\mathrm{w}$, and most of them are used as feed or discarded as waste disposal [2]. Dry SR contains about 50\% dietary fiber and $20 \%$ protein, plus considerable isoflavone, $\mathrm{s}$ aponin, mineral elements and other nutrients [3]. Die tary fiber is defined to be plant components that are $\mathrm{n}$ ot broken down by human digestive enzymes. In SR $\mathrm{t}$ he dietary fiber mainly consists of cellulose, hemicell

Copyright: (C) the author(s), publisher and licensee Technoscience Academy. This is an open-access article distributed under the terms of the Creative Commons Attribution Non-Commercial License, which permits unrestricted non-commercial use, distribution, and reproduction in any medium, provided the original work is properly cited 
ulose and pectin. Dietary fiber is the primary compon ent and bioactive constituent of SR. Based on the diffe rences of solubility, dietary fiber can be divided into $i$ nsoluble dietary fiber (IDF) and soluble dietary fiber (SDF). The two kinds of dietary fibers perform differe $\mathrm{nt}$ functions in the human body. IDF can increase the volume of feces and promote intestinal peristalsis, thu s preventing constipation, diarrhea and bowel cancer. SDF plays a more important role in modulating metab olic function, and has physiological functions such as enhancing glucose tolerance and lowering cholesterol level [4]. Diabetes researchers believe that consuming large amounts of soluble fiber may help control blood sugar levels after meals by slowing down the rate of $\mathrm{c}$ arbohydrate absorption in the intestine. Soluble fiber also lowers blood cholesterol and triglyceride levels $b$ $\mathrm{y}$ binding to cholesterol and helping to pass it out of $\mathrm{t}$ he body. Therefore, the composition proportion of sol uble components in dietary fiber is an important facto $r$ affecting its physiological function. It has been sugg ested that dietary fiber containing 30\%-50\% of SDF $p$ ossesses good quality. The portion of SDF in SR is ver y low, no more than $5 \%$ of total dietary fiber. This aff ects the development and utilization values of SR. Th erefore, increasing the SDF content is an important $\mathrm{w}$ ay to improve the quality and enhance the utilization of SR. Methods for increasing the SDF content and im proving the properties of SR have been reported, incl uding chemical, enzymatic, fermentation and physical [5]. Among these, physical methods present many ad vantages, such as short time, simple treatment, low co st and free of chemical residues. Steam explosion (SE) is a kind of physical method recently used in food pre treatment. The sample material is placed into a closed environment with high temperature and high pressur e, and the pores of material are filled with steam. Wh en the high pressure is released instantaneously, the $\mathrm{s}$ uperheated steam in the pores will rapidly gasify and $t$ he volume will drastically expand, resulting in the "ex plosion" of cells. The cell walls burst into porous and 1 ow molecular weight substances are released from insi de of cells. During SE treatment, the actions of acid-li ke hydrolysis, thermal degradation, mechanical fractu re and hydrogen bonds destruction could degrade and destroy the cellulose and hemicellulose into SDF [6]. SE technology has been in existence for more than 80 years and is most used in the pretreatment of wood fi ber to improve the accessibility of cellulose to enzyme and chemicals. In recent years, there are also a few re ports of SE used in foods, such as increasing the extrac t yield of flavonoids from fruits [7], and enhancing th e SDF content of orange peel [5]. But the research res ults on steam explosion treatment for dry SR were pu blished, but were not published on the research result $\mathrm{s}$ of increasing the ratio of soluble components by stea $\mathrm{m}$ explosion treatment for wet SR. If the wet SR prod uced in the soybean processing such as tofu and soybe an milk is treated by steam explosion, not only a lot of energy for drying can be saved, but also the content o $\mathrm{f}$ soluble dietary fiber can be increased. In this study, was evaluated the physicochemical properties of wet SR after determining the moisture content and the op timum steam explosion treatment conditions that max imize the content of soluble dietary fiber by Response Surface Methodology(RSM).

\section{METHODS AND MATERIAL}

\subsection{Materials}

\section{(1) Materials}

The SR of different moisture content was used the by product of tofu and soymilk processing in 2019. 5 .

\section{(2) Instruments}

QBS-80 type steam explosion machine

DZF-6050 type vacuum drier

(3) Period for experiment

From July 2019 to December 2019

\subsection{Method}

\section{(1) Preparation of SR sample}

The sample to treat by steam explosion was prepared $t$ wo class of wet SR of different moisture content and d ried SR. Due to the high moisture content and high vi scosity, wet SR is difficult to dry by the traditional dr 
ying methods. Therefore, vacuum drying technique $\mathrm{w}$ as applied to dry SR. In this method the sample was $d r$ ied to prepare the dry SR by a vacuum drier and grou nd into powder and was sieved.

(2) Selection of sample class for steam explosion treat ment

The dried SR and the wet SR was loaded into the reac tor of QBS-80 steam explosion machine, and then wat er steam was allowed to enter the reactor until $1.5 \mathrm{M}$ $\mathrm{Pa}$ and was kept for 90s, then the pressure was release $\mathrm{d}$ instantaneously. The SE treated SR samples were col lected, dried by a vacuum drier, ground and sieved wi th 80 mesh. The analysis of chemical composition on $t$ he SE treated SR sample was carried out.

(3) Determination of chemical components of steam e xplosion treated SR

Moisture content was measured by oven drying at 95$100{ }^{\circ} \mathrm{C}$ (AOAC 934.01)[8]. Protein content was estima ted by the Kjeldahl method (AOAC 960.52)[8]. Crude fat content was analyzed by the Soxhlet extraction me thod (AOAC 960.39)[8]. The ash content was determi ned by the method of combustion (AOAC 923.03)[8]. The contents of total dietary fiber (TDF), insoluble di etary fiber (IDF) and soluble dietary fiber (SDF) were assayed by the enzymatic-gravimetric method (AOAC 991.43)[8].

\section{(4) Single factor experiments}

- Selection of moisture content

The wet SR of different moisture content $(60 \%, 65 \%$, $70 \%, 75 \%, 80 \%, 85 \%)$ was loaded into the reactor of QBS-80 steam explosion machine, and then water stea $\mathrm{m}$ was allowed to enter the reactor until 1.5 $\mathrm{MPa}$ and was kept for 90s, then the pressure was released insta ntaneously. The SE treated SR samples were collected, dried by a vacuum drier, ground and sieved with 80 mesh. The analysis of the contents of soluble dietary $f$ iber (SDF) on the SE treated SR sample was carried ou t.

\section{- Selection of steam explosion treatment time}

The wet SR of moisture content $75 \%$ was loaded into the reactor of QBS-80 steam explosion machine, and $t$ hen water steam was allowed to enter the reactor unti
$11.5 \mathrm{MPa}$ and was kept for 30s, 60s, 90s, 120s and 150 $\mathrm{s}$, respectively, then the pressure was released instanta neously. The SE treated SR samples were collected, $d r$ ied by a vacuum drier, ground and sieved with $40-80$ mesh. The analysis of the contents of soluble dietary $\mathrm{f}$ iber (SDF) on the SE treated SR sample was carried ou t.

\section{- Selection of steam explosion pressure}

The wet SR of moisture content $75 \%$ was loaded into the reactor of QBS-80 steam explosion machine, and $t$ hen water steam was allowed to enter the reactor unti 1 the setting pressure $(0.5 \mathrm{MPa}, 1.0 \mathrm{MPa}, 1.5 \mathrm{MPa}, 2.0 \mathrm{M}$ $\mathrm{Pa}$ and $2.5 \mathrm{MPa}$ ) and was kept for $90 \mathrm{~s}$, then the pressur e was released instantaneously. The SE treated SR sam ples were collected, dried by a vacuum drier, ground a nd sieved with 80 mesh. The analysis of the contents of soluble dietary fiber (SDF) on the SE treated SR sa mple was carried out.

(5) Experimental methodology

RSM(response surface method) is a statistical method that used quantitative date from appropriate experime ntal design to determine optimal conditions. Therefor e, RSM with Box-Behnken was employed to determin e the optimum conditions for steam explosion treatme nt. The experimental factors were ascertained on the basis of the results of single factor experiments. In this work, the relationships between the responses and th e three selected variables were approximated by the $f$ ollowing second order polynomial function:

$$
Y=\beta_{0}+\sum_{i=1}^{a} \beta_{i} X_{i}+\sum_{i=1}^{a} \beta_{i i} X_{i}^{2}+\sum_{i j=1(i \neq 1)}^{a} \beta_{i j} X_{i} X_{j}
$$

Where $\mathrm{Y}$ is the calculated response function and $\mathrm{X}_{\mathrm{i}}$ is the corresponding actual value of variable. $\beta_{0}$ is the es timated regression coeffificient of the fitted response at the center point of the design; $\beta_{i}$ is the regression $c$ oeffificient for liner effect terms; $\beta_{\mathrm{ij}}$ is interaction effe cts; and $\beta_{\mathrm{ii}}$ is quadratic effects. 
The response of experiment design is the contents of $\mathrm{s}$ oluble dietary fiber (SDF) on the SE treated SR sample according to each experiment condition of design.

A Box-Behnken design was used to estimate the model coefficients. The levels of the three retained variables are indicated in Table 1.

Table 1. Experimental domain of the Box-Behnken

\begin{tabular}{c|c|c|c|c}
\multicolumn{5}{c}{ design } \\
\hline \multirow{2}{*}{ Factors } & \multirow{2}{*}{$\begin{array}{c}\text { Coded s } \\
\text { ymbols }\end{array}$} & -1 & 0 & +1 \\
& $\mathrm{X}_{1}$ & 65 & 75 & 85 \\
\hline Moisture/\% & & & \\
$\begin{array}{c}\text { Pressure Tim } \\
\text { e/S }\end{array}$ & $\mathrm{X}_{2}$ & 80 & 90 & 100 \\
$\begin{array}{c}\text { Explosion pre } \\
\text { ssure/MPa }\end{array}$ & $\mathrm{X}_{3}$ & 1 & 1.5 & 2 \\
\hline
\end{tabular}

(6) Determination of physicochemical properties of S E treated SR in the optimum condition

-Water solubility

Water solubility has an important impact on the devel opment and application of dietary fiber [12]. Higher water solubility can expand the application of SR in w ater-soluble food systems (such as beverages) and imp rove its physiological functions. The water solubility (WS) was determined according to the method of [9] with minor modification. SE treated SR ( $0.5 \mathrm{~g})$ was ge ntly mixed with $50 \mathrm{~mL}$ of distilled water in a beaker. The mixture was then stirred at $90{ }^{\circ} \mathrm{C}$ for $30 \mathrm{~min}$ in th ermostat water bath followed by centrifugation at 300 $0 \mathrm{rpm}$ for $15 \mathrm{~min}$. The supernatant was collected and dried by a vacuum drier. The residue was weighed. $\mathrm{T}$ he WS was calculated as follows :

$$
\mathrm{WS}(\%)=\frac{\mathrm{W}_{1}}{\mathrm{~W}} \times 100
$$

Where $\mathrm{W}_{1}$ and $\mathrm{W}$ are the weights of the residue after drying and sample, respectively.

-Water-holding capacity

The water-holding capacity (WHC) was determined a ccording to the method of [10] with minor modificati on. Briefly, $0.2 \mathrm{~g}$ of sample was mixed with $10 \mathrm{~mL}$ dist illed water at room temperature $\left(25^{\circ} \mathrm{C}\right)$ for $1 \mathrm{~h}$. After centrifugation at $3000 \mathrm{rpm}$ for $20 \mathrm{~min}$, the supernata nt was removed and the sediment with centrifuge tub e was weighed. The WHC was calculated as follows:

$$
\mathrm{WHC}(\mathrm{g} / \mathrm{g})=\frac{\mathrm{W}_{1}}{\mathrm{~W}}
$$

Where $\mathrm{W}_{1}$ is the weight of the sediment minus sampl e, and $\mathrm{W}$ is the weight of sample.

\section{-Oil-holding capacity}

The oil-holding capacity ( $\mathrm{OHC}$ ) was determined acco rding to the method[9] with minor modification. Brie fly, $1.0 \mathrm{~g}$ of sample was mixed with $5 \mathrm{~mL}$ soybean oil at $25{ }^{\circ} \mathrm{C}$ for $30 \mathrm{~min}$, shaking once every $5 \mathrm{~min}$. Then it was centrifuged at $4500 \mathrm{rpm}$ for $25 \mathrm{~min}$. The upper fr ee oil was removed and the residue with centrifuge tu be was weighed. The $\mathrm{OHC}$ was calculated as follows:

$$
\mathrm{OHC}(\mathrm{g} / \mathrm{g})=\frac{\mathrm{W}_{1}}{\mathrm{~W}}
$$

Where $\mathrm{W}_{1}$ is the weight of the residue minus sample, and $\mathrm{W}$ is the weight of sample.

- Swelling capacity

The swelling capacity (SC) was measured according to the method[11] with minor modification. $1.0 \mathrm{~g}$ of sa mple was placed in a test tube, $10 \mathrm{~mL}$ of water was ad ded and it was hydrated for $24 \mathrm{~h}$ at $25^{\circ} \mathrm{C}$. Thevolume of the sample was recorded. The SC was calculated as follows:

$$
\mathrm{SC}(\mathrm{mL} / \mathrm{g})=\frac{\mathrm{v}}{\mathrm{W}}
$$

Where $\mathrm{V}$ is the final volume occupied by sample and $\mathrm{W}$ is the weight of sample.

\subsection{Statistical analysis}

All experiments were triplicated. Analysis of variance (ANOVA) of the results was performed using DesignExpert version 11. The statistical significance of the $m$ odel terms was determined by calculating the $\mathrm{F}$-value at confidence levels of $95 \%(\mathrm{P}<0.05)$ and $99 \%(\mathrm{P}<0.0$ 1). Data were subjected to analysis of variance (ANO VA) using the software package SPSS version 26 for Windows. Significant differences $(\mathrm{p}<0.05)$ of means were determined by the Duncan's multiple range test. 


\section{RESULTS}

\subsection{Effect of steam explosion on the composition and content of dietary fiber of SR}

The SDF content in SR was very low, which affects its nutritional value and application range. Therefore, in creasing SDF content is one of the key measures for $i$ mproving the quality of SR. SE treatment was applied to increase SDF content of SR in this work and the eff ects of SE strength (explosion pressure and keep time) on the composition and content of dietary fiber of SR were studied.

Table 2. The change of the composition and content o $\mathrm{f}$ dietary fiber of SR by steam explosion treatment $/ \%$

\begin{tabular}{c|c|c|c|c|c|c}
\hline $\begin{array}{c}\text { Mat } \\
\text { eria } \\
1\end{array}$ & $\begin{array}{c}\text { Crude } \\
\mathrm{d} \text { Ash }\end{array}$ & $\begin{array}{c}\text { Crude } \\
\mathrm{d} \\
\text { Protei } \\
\mathrm{n}\end{array}$ & $\begin{array}{c}\text { Crud } \\
\text { ed } \\
\text { Fat }\end{array}$ & TDF & IDF & SDF \\
\hline Drie & $4.65 \pm 0$. & $20.41^{ \pm}$ & $13.27 \pm$ & $55.62 \pm$ & $33.16 \pm$ & 22.49 \\
$\mathrm{dSR}$ & $43^{\mathrm{b}}$ & $0.21^{\mathrm{b}}$ & $0.24^{\mathrm{b}}$ & $0.61^{\mathrm{b}}$ & $0.46^{\mathrm{a}}$ & $\pm 0.66^{\mathrm{b}}$ \\
$\mathrm{We}$ & $4.65 \pm 0$. & $20.36 \pm$ & $13.2 \pm$ & $55.65 \pm$ & $30.39 \pm$ & 25.26 \\
$\mathrm{t} \mathrm{S}$ & $26^{\mathrm{a}}$ & $0.32^{\mathrm{a}}$ & $0.45^{\mathrm{a}}$ & $0.43^{\mathrm{a}}$ & $0.57^{\mathrm{b}}$ & $\pm 0.79^{\mathrm{a}}$ \\
$\mathrm{R}$ & & & & & & \\
\hline
\end{tabular}

※ Data with different small letters $\left(\mathrm{a}^{\sim} \mathrm{b}\right)$ in a column are significantly different at $\mathrm{p}<0.05$ by Duncan's multi ple range test.

The change of chemical composition and content of $d$ ietary fiber of dried SR and wet SR by steam explosio $\mathrm{n}$ treatment is shown in Table 1. As shown Table 1, th e composition and the TDF content of dried SR and $w$ et SR was no different after steam explosion treatment, but on the SDF content, the wet SR was higher than $\mathrm{t}$ he dried SR. The reason is that a lot of low molecular is produced and released the hydrophilic group, the $c$ ontent of soluble material is increased through the pol ymerization degree of IDF is decreased and the polym er is dissolved. Thus, the appropriate moisture conten $t$ should be chosen to get maximum SDF content. The reason for SDF content enhancement is that SE treat ment of wet SR was more effective loosen the tight str ucture of fiber than dried SR.

\subsection{The results of single factor experiments}

(1) Determination of SR moisture content

The change of SDF content according to SR moisture co ntent in the steam explosion treatment is shown in Figu re 1 .

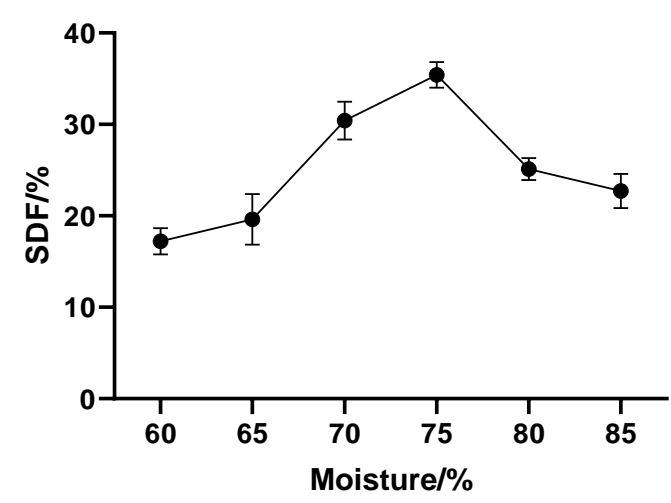

Figure 1. The change of SDF content according to SR moisture content in the steam explosion treatment As can be seen from Figure 1, in the steam explosion $t$ reatment the SDF content of wet SR was rapidly incre ased from moisture content $70 \%$ and when the moistu re content was higher than $80 \%$, the SDF content was gradually decreased. Thus, the SDF content was high est in the moisture content 75\%, therefore the moistu re content of SR selected 75\% to carry out the followi ng studies.

(2) Determination of steam explosion treatment time The change of SDF content according to steam explosio $\mathrm{n}$ treatment time is shown in Figure 2.

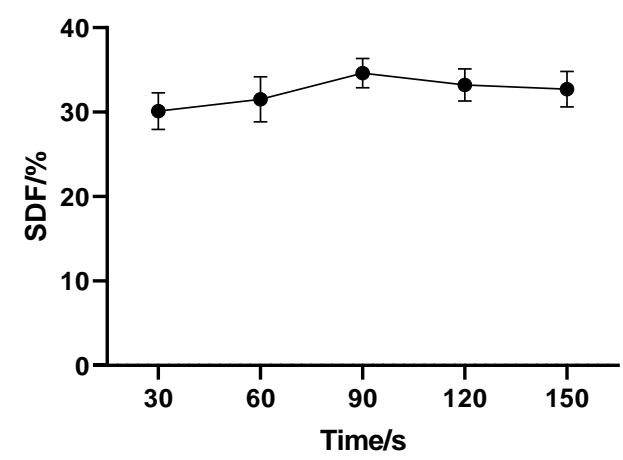

Figure 2. The change of SDF content according to stea $\mathrm{m}$ explosion treatment time 
As can be seen from Figure 2, with the prolong of stea m explosion treatment time, the SDF content gradually increased, reaching the highest when steam explosion treatment time was 90s, and then the content decreas ed slightly. Therefore, 90s was selected as the steam ex plosion treatment time.

(3) Determination of steam explosion pressure The change of SDF content according to steam explosio $\mathrm{n}$ pressure is shown in Figure 3.

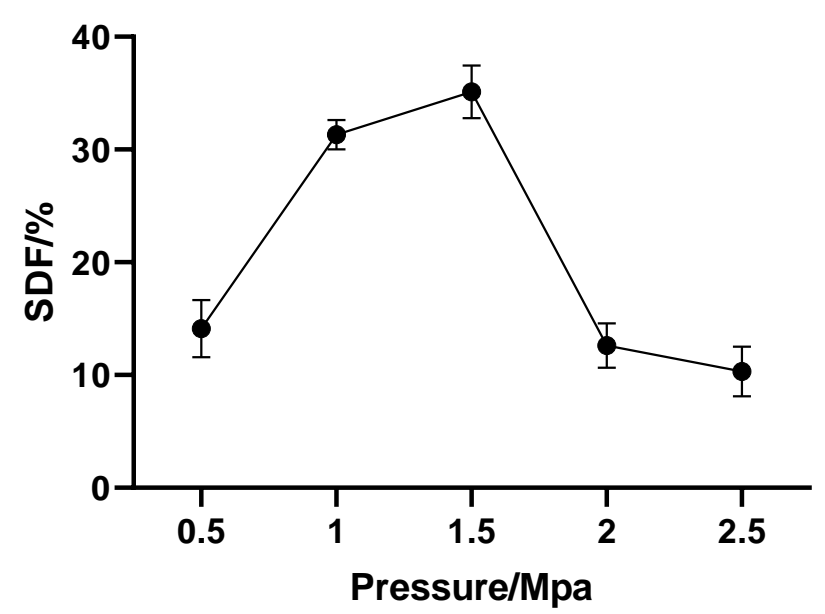

Figure 3. The change of SDF content according to stea $\mathrm{m}$ explosion pressure

As can be seen from Figure 3, with the increasing of st eam explosion pressure, the SDF content increased rapi dly, reaching the highest when steam explosion pressu re was $1.5 \mathrm{MPa}$, and then the content decreased rapidl y. Therefore, 1.5MPa was selected as the steam explosi on pressure.

\subsection{The results and analysis of response surface experiment}

\section{(1) Response measurements}

Experimental values obtained for SDF content of SE tr eated wet SR are shown in Table 2. The SDF content $r$ anged from $33.65 \%$ to $36.49 \%$
Table 3. Box-Behnken design and SDF content

\begin{tabular}{|c|c|c|c|c|}
\hline \multirow{2}{*}{$\begin{array}{c}\text { Run } \\
\mathrm{s}\end{array}$} & \multicolumn{3}{|c|}{ Factors } & \multirow{2}{*}{$\begin{array}{c}\text { SDF } \\
\text { content/ } \\
\%\end{array}$} \\
\hline & $\begin{array}{c}\mathrm{X}_{1}: \text { Moistu } \\
\text { re } / \%\end{array}$ & $\begin{array}{l}\mathrm{X}_{2}: \text { Pressu } \\
\text { re time/S }\end{array}$ & $\begin{array}{c}\mathrm{X}_{3}: \text { Explosio } \\
\mathrm{n} \\
\text { pressure } / \mathrm{M} \\
\mathrm{Pa}\end{array}$ & \\
\hline 1 & 65 & 80 & 1.5 & 34.29 \\
\hline 2 & 85 & 80 & 1.5 & 34.61 \\
\hline 3 & 65 & 100 & 1.5 & 33.65 \\
\hline 4 & 85 & 100 & 1.5 & 34.68 \\
\hline 5 & 65 & 90 & 1 & 34.08 \\
\hline 6 & 85 & 90 & 1 & 34.86 \\
\hline 7 & 65 & 90 & 2 & 34.54 \\
\hline 8 & 85 & 90 & 2 & 35.08 \\
\hline 9 & 75 & 80 & 1 & 35.46 \\
\hline 10 & 75 & 100 & 1 & 35.02 \\
\hline 11 & 75 & 80 & 2 & 35.68 \\
\hline 12 & 75 & 100 & 2 & 35.42 \\
\hline 13 & 75 & 90 & 1.5 & 36.49 \\
\hline 14 & 75 & 90 & 1.5 & 36.45 \\
\hline 15 & 75 & 90 & 1.5 & 36.5 \\
\hline 16 & 75 & 90 & 1.5 & 36.46 \\
\hline 17 & 75 & 90 & 1.5 & 36.44 \\
\hline
\end{tabular}

(2) Estimated model

RSM was used to evaluate the effects of variables on t he SDF content, then build a model to find the best se tting of the variables that maximize the SDF content a nd study the combined relationships between the con ditions and the SDF content. The second-order model $s$ in term of coded variable are given by the following equation.

$\mathrm{Y}=36.47+0.3327 \mathrm{X}_{1}-0.1594 \mathrm{X}_{2}+0.1604 \mathrm{X}_{3}+0$.

$1781 \mathrm{X}_{1} \mathrm{X}_{2}-0.06 \mathrm{X}_{1} \mathrm{X}_{3}+0.0463 \mathrm{X}_{2} \mathrm{X}_{3}-1.46 \mathrm{X}_{1}^{2}-0$. $7023 X_{2}^{2}-0.3696 X_{3}^{2}(6)$

The correction coefficient of the model $\mathrm{R}^{2}=0.9997$ and $\mathrm{R}_{\mathrm{Adj}^{2}}=0.9993$ indicate that the model has good fitting degree and small experimental error, so the model is $\mathrm{s}$ uitable. The results of analysis of variance (ANOVA) $\mathrm{f}$ or SDF content are given in Table 4 . As can be seen, $t$ 
he model F-value of 2460.51 with a low probability Pvalue of less than 0.0001 indicted high significance of the model. The lack of fit for an F-value of 1.46 meant that this term was not significantly relative to the pur e error, the nonsignificant value of lack fit $(<0.05)$ sho wed that the quadratic model was valid for this study.
From the results in Table 4, the liner coefficient, the i nteraction and the quadratic coefficient of all factors were significant by t-test at a level of 0.01 . The all of moisture, pressure time and explosion pressure had sh own to be the important variable of this model.

Table 4. Analysis of variance of Box-Behnken design (BBD)

\begin{tabular}{c|c|c|c|c|c|c}
\hline Source & Sum of Squares & df & Mean Square & F-value & P-value & Significant \\
\hline Model & 13.97 & 9 & 1.55 & 2460.51 & $<0.0001$ & ${ }^{* *}$ \\
$\mathrm{X}_{1}$-Moisture & 0.8854 & 1 & 0.8854 & 1403.00 & $<0.0001$ & ${ }^{* *}$ \\
$\mathrm{X}_{2}$-Pressure time & 0.2034 & 1 & 0.2034 & 322.29 & $<0.0001$ & ${ }^{* *}$ \\
$\mathrm{X}_{3}$-Explosion pressure & 0.2059 & 1 & 0.2059 & 326.29 & $<0.0001$ & ${ }^{* *}$ \\
$\mathrm{X}_{1} \mathrm{X}_{2}$ & 0.1269 & 1 & 0.1269 & 201.16 & $<0.0001$ & ${ }^{* *}$ \\
$\mathrm{X}_{1} \mathrm{X}_{3}$ & 0.0144 & 1 & 0.0144 & 22.85 & 0.0020 & ${ }^{* *}$ \\
$\mathrm{X}_{2} \mathrm{X}^{*}$ & 0.0086 & 1 & 0.0086 & 13.56 & 0.0078 & ${ }^{* *}$ \\
$\mathrm{X}_{1}{ }^{2}$ & 8.95 & 1 & 8.95 & 14186.42 & $<0.0001$ & ${ }^{* *}$ \\
$\mathrm{X}_{2}{ }^{2}$ & 2.08 & 1 & 2.08 & 3290.47 & $<0.0001$ & ${ }^{* *}$ \\
$\mathrm{X}_{3}{ }^{2}$ & 0.5751 & 1 & 0.5751 & 911.36 & $<0.0001$ & ${ }^{* *}$ \\
Residual & 0.0044 & 7 & 0.0006 & & & \\
Lack of Fit & 0.0023 & 3 & 0.0008 & 1.46 & 0.3514 & not significant \\
Pure Error & 0.0021 & 4 & 0.0005 & & & \\
Cor Total & 13.98 & 16 & & & & \\
\hline
\end{tabular}

(3) Analysis of response surface

The relationships between the experimental variables and the responses are illustrated in three dimensional representations of the response surfaces. These plots a re presented in Figure 4, respectively. The main goal o $\mathrm{f}$ response surface is to track efficiently for the optimu $\mathrm{m}$ values of the variables such that the response is ma ximized. By analyzing the plots, the best response ran ge can be calculated.

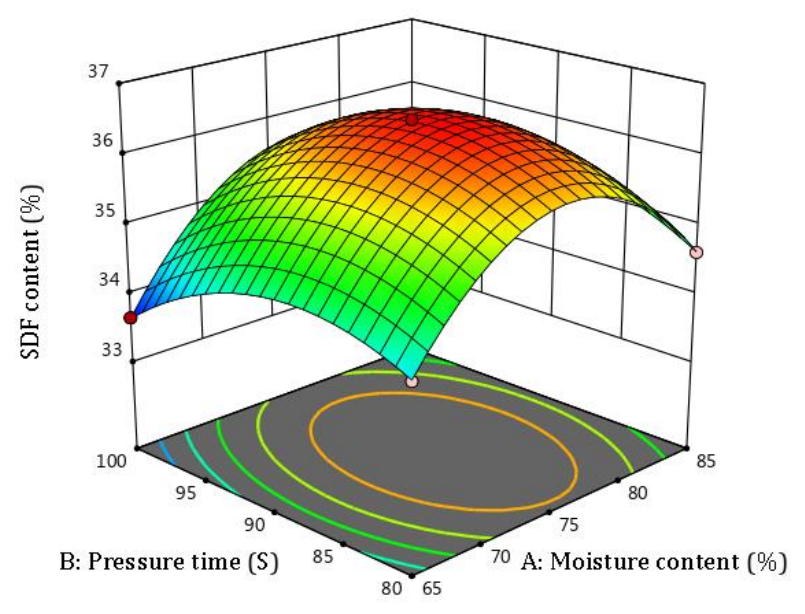



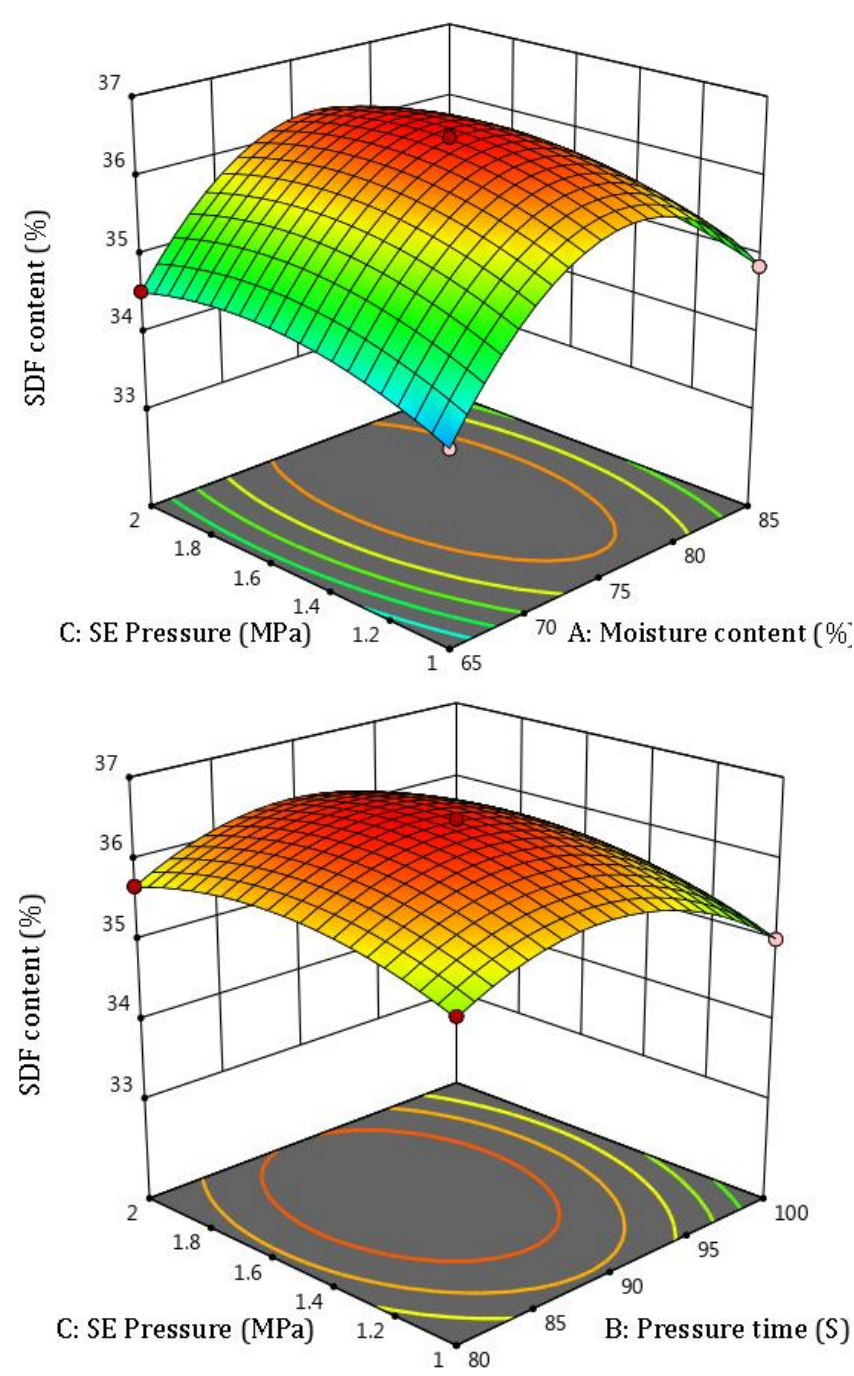

Figure 4. Response surface plots and contour lines of e

ffects of interaction between each factor

Figure 4 shows the three-dimensional response surfac e plot for SDF content of SE treated SR. It can be seen from Figure 4A, 4B and 4C that the SDF content incr eases firstly, and decreases afterwards with the increas e of pressure time, SE pressure and moisture content, i $t$ could be observed that general trends of the three fa ctors are similar. The significant negative linear effect of $\mathrm{X}_{2}$ (pressure time) and the negative square effect of $\mathrm{X}_{1}{ }^{2}$ (moisture content), $\mathrm{X}_{2}{ }^{2}$ (pressure time), $\mathrm{X}_{3}{ }^{2}$ (SE pr essure) in the SDF content were presented in Figure 4 A. Therefore, the maximal SDF content was obtained at the low level of pressure time (88S), the middle lev el of moisture content(76.3\%), the middle level of SE pressure(1.7MPa). The effects of the three independe nt variables on the response value (SDF content) were visually described by the 3-D plot (Figure 4A-4C). Th e results showed that the low level of pressure time (8 $8 S)$, the middle level of moisture content(76.3\%), the middle level of SE pressure(1.7MPa), led to the optim al results.

\subsection{The physicochemical properties of $S E$ treated $S R$ in the optimum condition}

The physicochemical properties of SE treated SR in th e optimum condition is shown in Figure 5.

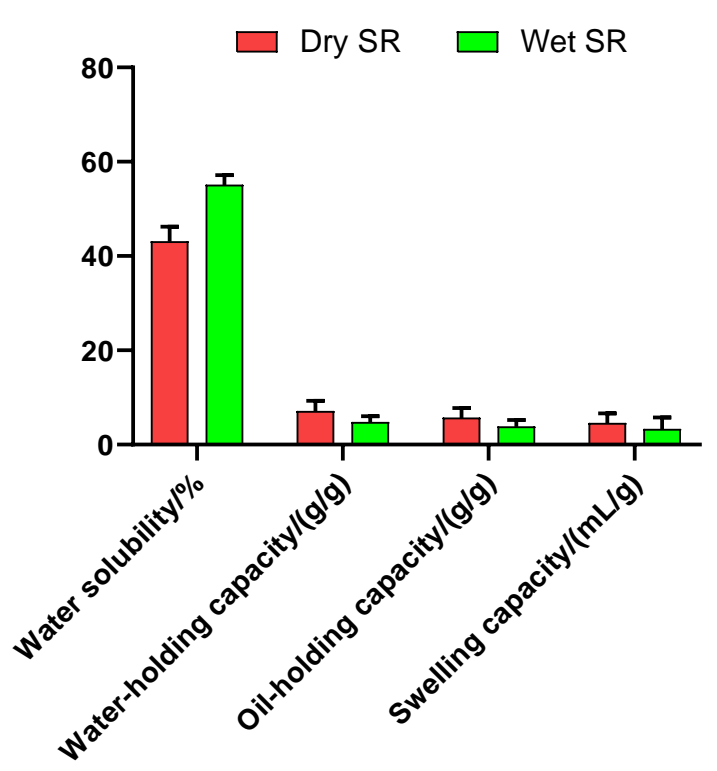

Figure 5. The analysis result on the physicochemical propert ies of SE treated SR in the optimum condition

As can be seen from Figure 5, the water solubility of wet SR increased than dry SR after SE treatment. This may be due to the fact that SE treatment more effecti ve loosened the tight structure of dietary fiber in SR o $\mathrm{f}$ high moisture content and degraded some insoluble dietary fiber, resulting in more hydrophilic groups bei ng exposed, thus much enhancing the water solubility of SR. The swelling capacity of wet SR decreased afte $r$ SE treatment. This might be caused that the original structure of dietary fiber was easily destroyed after SE treatment in the high moisture content of substance, and the amount of macromolecular substances reduce $\mathrm{d}$, both leading to the decrease of swelling capacity. $\mathrm{T}$ 
he oil holding capacity of SR decreased after SE treat ment, caused that SE treatment is effective depolymer ized proteins of wet SR, which might lead to the decr ease of oil holding capacity. Furthermore, the porous structure and large specific surface area are beneficial for the absorption property of dietary fiber. The water holding capacity of wet SR decreased after SE treatm ent. The reason is that the SDF of wet SR is more incr eased than the dry SR after SE treatment, on the contr ary, because the IDF of wet SR is decreased, the water holding capacity of wet SR is decreased.

\section{DISCUSSION}

Soybean residue(SR) is a by-product of soymilk produ ction with a rich nutritional profile, particularly in $\mathrm{pr}$ oteins, fibers, lipids, and bioactive components. SR ha $s$ the potential for value-added production and utilizat ion choices that, at the same time, deliver on the pro mise of increased economic advantages along with a $r$ eduction in environmental pollution. However, the ut ilization of SR is very low, and most of them are used as feed or discarded as waste disposal. Dry SR contains about $50 \%$ dietary fiber and $20 \%$ protein, plus consid erable isoflavone, saponin, mineral elements and othe $r$ nutrients. SDF lowers blood cholesterol and triglyce ride levels by binding to cholesterol and helping to pa ss it out of the body. Therefore, the composition prop ortion of soluble components in dietary fiber is an im portant factor affecting its physiological function. The portion of SDF in SR is very low, no more than 5\% of total dietary fiber. Therefore, increasing the SDF cont ent is an important way to improve the quality and en hance the utilization of SR. Methods for increasing th e SDF content and improving the properties of SR hav e been reported, including chemical, enzymatic, ferm entation and physical. Steam explosion (SE) is a kind of physical method recently used in food pretreatmen t. During SE treatment, the actions of acid-like hydrol ysis, thermal degradation, mechanical fracture and hy drogen bonds destruction could degrade and destroy $\mathrm{t}$ he cellulose and hemicellulose into SDF. In this study, the insoluble dietary fiber of SR converted to soluble dietary fiber by SE treatment and increased the conte nt of soluble dietary fiber, and optimized the conditio $\mathrm{n}$ of SE treatment processing by response surface met hod(RSM). Firstly, ascertained the effect of the SE tre atment on the wet SR sample, the result was shown $t$ hat the SE treatment on wet SR has more excellent in the improvement of SDF content, SDF content increa sed than the dried SR. Secondly, optimized the SE tre atment on wet SR. Through the single factors experim ents, determined the optimal blocks of each factor, on the basis of these, the experimental design carried out by Response Surface Methodology and obtained the o ptimum condition. As can be seen from Figure 4 and $t$ able 4 , the results showed that the optimum conditio ns was: water content of $76.3 \%$, steam explosion time of $88 \mathrm{~S}$, steam explosion pressure of $1.7 \mathrm{MPa}$; on the $\mathrm{c}$ onditions, the theoretical content of SDF was 36.5\%. Through the analysis on the physicochemical propert ies of SE treated SR in the optimum condition, determ ined that water solubility of SR increased significantly, while swelling capacity, oil and water holding capaci ties decreased after SE treatment. The water solubility of wet SR increased than dry SR after SE treatment. T his may be due to the fact that SE treatment more effe ctive loosened the tight structure of dietary fiber in $\mathrm{S}$ $\mathrm{R}$ of high moisture content and degraded some insolu ble dietary fiber, resulting in more hydrophilic groups being exposed, thus much enhancing the water solub ility of SR. The swelling capacity of wet SR decreased after SE treatment. This might be caused that the origi nal structure of dietary fiber was easily destroyed afte r SE treatment in the high moisture content of substa nce, and the amount of macromolecular substances re duced, both leading to the decrease of swelling capaci ty. The oil holding capacity of SR decreased after SE t reatment, caused that $\mathrm{SE}$ treatment is effective depoly merized proteins of wet SR, which might lead to the $d$ ecrease of oil holding capacity. Furthermore, the poro us structure and large specific surface area are benefic ial for the absorption property of dietary fiber. The $\mathrm{w}$ 
ater holding capacity of wet SR decreased after SE tre atment. The reason is that the SDF of wet SR is more $\mathrm{i}$ ncreased than the dry SR after SE treatment, on the c ontrary, because the IDF of wet SR is decreased, the water holding capacity of wet SR is decreased.

\section{CONCLUSION}

In this study, ascertained the effect of the SE treatmen $t$ on the wet SR sample, the result was shown that the SE treatment on wet SR has more excellent in the im provement of SDF content, SDF content increasedtha $\mathrm{n}$ the dried SR. And optimized the SE treatment on $\mathrm{w}$ et $\mathrm{SR}$, through the single factors experiments, determi ned the optimal blocks of each factor, on the basis of $t$ hese, the experimental design carried out by Response Surface Methodology and obtained the optimum con dition. The results showed that the optimum conditio ns was: water content of $76.3 \%$, , steam explosion ti me of $88 \mathrm{~S}$, steam explosion pressure of $1.7 \mathrm{MPa}$; on $\mathrm{t}$ he conditions, the theoretical content of SF was 36. $5 \%$. Through the analysis on the physicochemical pro perties of SE treated SR in the optimum condition, det ermined that water solubility of SR increased significa ntly, while swelling capacity, oil and water holding ca pacities decreased after SE treatment. Further researc $h$ works will be done to investigate the change of bioa ctivities of SE treated SR and the application effects o $\mathrm{n}$ foods such as flour products, beverages, etc.

\section{REFERENCES}

[1]. Li B , Qiao M, Lu F . Composition, Nutrition, and Utilization of Okara (Soybean Residue)J]. Food Reviews International, 2012, 28(3):231-252.

[2]. Harthan L B , Cherney D J R . Okara as a protein supplement affects feed intake and milk composition of ewes and growth performance of lambsJ]. Animal Nutrition, 2017, 3(2):171-174.

[3]. Jankowiak L, Trifunovic O, Boom R M , et al. The potential of crude okara for isoflavone productionJ]. Journal of Food Engineering, 2014, 124(mar.):166-172.
[4]. Bosaeus I . Fibre effects on intestinal functions (diarrhoea, constipation and irritable bowel syndrome)J]. Clinical Nutrition Supplements, 2004, 1(2):33-38.

[5]. Preparation and physicochemical properties of soluble dietary fiber from orange peel assisted by steam explosion and dilute acid soakingJ]. Food Chemistry, 2015, 185:90-98.

[6]. Kang F F , Yang W , Fei L U , et al. Reasearch progress on the methods for quality improvement of okaraJ]. Science and Technology of Food Industry, 2016.

[7]. Yan J . Study on Steam Exploded Technology. 2009.

[8]. Otles S , Ozyurt V H . Classical Wet Chemistry MethodsJ]. Springer Berlin Heidelberg, 2014.

[9]. Zhang M, Liang Y, Pei $Y$, et al. Effect of Process on Physicochemical Properties of Oat Bran Soluble Dietary Fiber]]. Journal of Food Science, 2009, 74(8):72-80.

[10]. Mateos-Aparicio I , Mateos-Peinado C , P Rupérez. High hydrostatic pressure improves the functionality of dietary fibre in okara by-product from soybeanJ]. Innovative Food Science \& Emerging Technologies, 2010, 11(3):445-450.

[11]. Min Z , Xin B , Zhang Z . Extrusion process improves the functionality of soluble dietary fiber in oat branJ]. Journal of Cereal Science, 2011, 54(1):98-103.

[12]. Chau C F , Huang Y L . Comparison of the chemical composition and physicochemical properties of different fibers prepared from the peel of Citrus sinensis L. Cv. Liucheng.J]. J Agric Food Chem, 2003, 51(9):2615-2618.

\section{Cite this article as :}

TongSop Ri, SongRok Uh, ChonBong Song, HyonDok Pak, YongChol Ju, SongNam Ri, OkJong Zhang, "Study on the Optimization of the Soluble Dietary Fiber Content of Soybean Residue by Steam Explosion Pretreatment", International Journal of Scientific Research in Science, Engineering and Technology (IJSRSET), Online ISSN : 2394-4099, Print ISSN : 2395-1990, Volume 8 Issue 3, pp. 36-39, May-June 2021. Available at doi : https://doi.org/10.32628/IJSRSET21835 Journal URL : https://ijsrset.com/IJSRSET21835 